\title{
Climate Variability in a Coupled GCM. Part I: The Tropical Pacific
}

\author{
M. LAtif, A. Sterl, E. Maier-Reimer, AND M. M. JunGe \\ Max-Planck-Institut für Meteorologie, Hamburg, Germany \\ (Manuscript received 14 October 1991, in final form 27 March 1992)
}

\begin{abstract}
A 26-year integration has been performed with a coupled ocean-atmosphere general circulation model (CGCM). The oceanic part resolves all three oceans in the latitude band $70^{\circ} \mathrm{N}-70^{\circ} \mathrm{S}$ but is dynamically active only between $30^{\circ} \mathrm{N}$ and $30^{\circ} \mathrm{S}$. The atmosphere is represented by a global low-order spectral model. The coupled model was forced by seasonally varying insolation. Although the simulated time-averaged mean conditions in both atmosphere and ocean show significant deviations from the observed climatology, the CGCM realistically simulates the interannual variability in the tropical Pacific. In particular, the CGCM simulates an irregular ENSO with a preferred time scale of about 3 years.

The mechanism for the simulated interannual variability in the tropical Pacific is related to both the "delayed action oscillator" and the "slow SST mode." It therefore appears likely that either both modes can coexist or they degenerate to one mode within certain locations of the parameter space. This hypothesis is also supported by calculations performed with simplified coupled models, in which the atmospheric GCM was replaced by linear steady-state atmosphere models. Further, evidence is found for an eastward migration of zonal wind anomalies over the western Pacific prior to the extremes of the simulated ENSO, indicating a link to circulation systems over Asia.

Because an earlier version of the CGCM did not simulate interannual variability in the tropical Pacific, additional experiments with a simplified coupled model have been conducted to study the sensitivity of coupled systems to varying mean oceanic background conditions. It is shown that even modest changes in the background conditions can push the coupled system from one flow regime into another.
\end{abstract}

\section{Introduction}

Large-scale air-sea interactions contribute considerably to climate variability on a wide range of time scales. On the short-range climatic time scale, the El Niño-Southern Oscillation (ENSO) phenomenon is the most prominent representative of such air-sea interactions. Uncoupled simulations of ENSO, using separate ocean and atmosphere models, have shown that the individual models can reproduce the basic aspects of the ENSO-related interannual variability, provided that the observed boundary conditions are prescribed (e.g., Busalacchi et al. 1983; Philander and Seigel 1985; Lau 1985; Latif 1987; Seager et al. 1989; Latif et al. 1990; Barnett et al. 1991). These studies have also been very useful for gaining insight into the physics of ENSO. However, a complete description of ENSO and further insight into its dynamics can be obtained only by coupled ocean-atmosphere models.

A hierarchy of coupled ocean-atmosphere models has been developed, ranging from simple and intermediate models (e.g., McCreary 1983; Zebiak and

Corresponding author address: Dr. Mojib Latif, Max-Planck-Institut für Meteorologie, Bundesstrasse 55, D-2000 Hamburg 13, Federal Republic of Germany.
Cane 1987; Schopf and Suarez 1988; Neelin 1990) to sophisticated coupled general circulation models (CGCMs) developed at different institutions (e.g., Latif et al. 1988a,b; Gordon 1989; Meehl 1990; Philander et al. 1992). Neelin et al. (1992) summarized the coupled behaviors found in a variety of coupled models. They found a large range of possible behaviors among the different coupled models. Those coupled models that simulate interannual variability have roughly been classified into those with standing and those with propagating SST anomalies. This classification also provides a crude indication of the underlying mechanism for the interannual variability simulated in the different coupled models. Standing SST anomalies are probably indicators of the "delayed action oscillator" (Schopf and Suarez 1988), according to which the phase reversal between ENSO (warm) and anti-ENSO (cold) conditions can be attributed to the propagation of equatorial waves and their reflection at meridional boundaries. In contrast, propagating SST anomalies might at first order be related to the "slow SST modes" (Neelin 1991), in which spatial and temporal phase differences between SST and zonal wind play a crucial role and wave propagation is unimportant.

In this paper, we present the latest version of our coupled general circulation model and investigate the climatology and the variability simulated by the CGCM 
in a 26-year integration. Our study is similar to the one described by Philander et al. (1992), since we coupled a high-resolution ocean general circulation model (OGCM) to a low-order atmosphere general circulation model (AGCM). However, our coupled simulation differs in several aspects from the one of Philander et al. (1992). The most important differences are the inclusion of the annual cycle, all three oceans, and interactive clouds. Here we focus on the tropical Pacific only. Results from the other oceans will be presented in a forthcoming paper.

Our CGCM simulates considerable interannual variability in the tropical Pacific, in contrast to an earlier version described by Latif et al. (1988a,b). The lack of interannual variability in the simulation with that earlier version was attributed mainly to three reasons: the weak variability in the atmosphere model, the too diffusive ocean model, and the application of the "flux correction" scheme (Sausen et al. 1988) to couple the individual model components. Although many changes have been made in the individual components, we believe that the omission of the flux correction in our new simulation is the main reason for the oscillatory behavior found. In order to test this hypothesis, we conducted additional simulations with a simplified coupled model, in which the atmosphere was replaced by a linear steady-state model. It is shown that low-frequency variability can be entirely suppressed by varying the mean oceanic conditions by increasing the mean background wind stress by only $10 \%$.

We have found that the mechanism for the interannual variability simulated by the CGCM is related to both the delayed action oscillator (Schopf and Suarez 1988; Philander 1990) and the slow SST mode (Neelin 1991). Episodes dominated by either the delayed action oscillator or the SST mode are found, as well as periods when the two coupled modes seem to coexist or to merge to one mode. Interestingly, the coupled model also simulates the observed eastward propagation of zonal wind anomalies from the western into the central Pacific prior to the extremes of the model ENSO.

This paper is organized as follows. In section 2, we describe the individual model components and the coupling technique. We then describe in section 3 the simulated annual mean conditions and the annual cycle. Section 4 deals with the simulated interannual variability. In section 5 , we present the additional sensitivity runs performed with the ocean model run in an uncoupled mode and with simplified coupled ocean-atmosphere models. We conclude the paper with a brief summary and a discussion of the results in section 6 .

\section{Model}

The ocean model is based on the OGCM described by Latif (1987). Its ability to simulate interannual variability in the tropical Pacific has been investigated in a series of papers. The most comprehensive analysis can be found in Barnett et al. (1991). A slightly different version has been used by Luksch and von Storch (1992) in their investigation of the low-frequency SST variability in the North Pacific. The model is based on primitive equations that have been simplified by making use of the hydrostatic and Boussinesq approximations. Dynamically active salinity is included. The density is calculated by the "Unesco" formula given by Gill (1982). The model also includes bottom topography. The OGCM is zonally global with a constant zonal resolution of $5^{\circ}$. The meridional domain extends from $70^{\circ} \mathrm{N}$ to $70^{\circ} \mathrm{S}$. Within the region $10^{\circ} \mathrm{N}-10^{\circ} \mathrm{S}$ the meridional resolution is rather high at $0.5^{\circ}$ in order to resolve the equatorial waves and the narrow equatorial upwelling region. It then decreases to $1^{\circ}$ at $\pm 20^{\circ}$ and to $5^{\circ}$ at $\pm 30^{\circ}$ and remains constant poleward. Vertically there are 17 irregulary placed levels with 10 levels in the upper $300 \mathrm{~m}$. The ocean model is dynamically active only in the region $30^{\circ} \mathrm{N}-30^{\circ} \mathrm{S}$. Outside of this region temperature and salinity are heavily restricted by a restoring to Levitus (1982) climatology using a Newtonian formulation with a time constant of about 300 days. Mixing coefficients are dependent on the Richardson number. In contrast to the earlier version of the model used by Latif (1987) and Luksch and von Storch (1992), the numerics have been changed to be less diffusive. The original fully implicit treatment of the linear terms in the time-stepping scheme has been changed to a semi-implicit scheme. We also changed the treatment of the advective terms from an upstream to a predictor-corrector scheme. Further details on the ocean model can be found in Sterl (1991).

The atmosphere model is the Hamburg version of the "T21" AGCM (cycle 31) of the European Centre for Medium-Range Weather Forecasts (ECMWF). It is a low-order spectral GCM, which explicitly resolves waves up to zonal wavenumber 21 .

The nonlinear terms are calculated on a $64 \times 32$ Gaussian grid, which yields a horizontal resolution of about $5.6^{\circ} \times 5.6^{\circ}$. There are 19 levels in the vertical, defined on $\sigma$ surfaces in the lower troposphere and on $p$ surfaces in the upper troposphere and the stratosphere. The model includes standard physics, such as a complete hydrological cycle and interactive clouds. The T21 model has been applied in various climate simulations and response experiments, which are summarized in two reports (Fischer 1987; von Storch 1988). As shown in Biercamp and von Storch (1987) and in Latif et al. (1988b), the model fails to simulate trade winds of reasonable strength. The simulated trades are only about half as strong as the observed ones. The low-frequency behavior of the model when forced by observed SSTs is described in detail by Latif et al. (1990) and Barnett et al. (1991). As shown in the two studies, the T21 model simulates reasonably well the basic aspects of the Southern Oscillation. However, although the phase of the Southern Oscil- 
lation is simulated with some success, the strength of the variations is seriously underestimated.

The two models have been coupled without applying any correction. They interact over all three oceans in the region $30^{\circ} \mathrm{N}-30^{\circ} \mathrm{S}$. The ocean model is forced by the surface wind stress, the heat flux, and the freshwater flux simulated by the atmosphere model, which in turn is forced by the SST simulated by the ocean model. Outside the coupling region, boundary conditions are prescribed from climatology. Information is exchanged between the two models every oceanic time step, that is, every 2 hours. The coupled model is forced by seasonally varying insolation. The oceanic initial conditions are those simulated at the end of a 29-year integration with climatological forcing. The "climatological run" was initialized with Levitus (1982) climatology with the ocean being at rest. The atmospheric initial conditions for the coupled integration are taken from the analysis for 1 January 1988. The integration is started at 1 January and is continued for 26 years.

\section{Annual mean fields and annual cycle}

\section{a. Annual mean fields}

Although our CGCM was forced by seasonally varying insolation, the simulated annual mean fields are discussed first. The annual mean SST (Fig. 1a) is too zonal and shows an only weakly developed equatorial cold water tongue in the Pacific, which is separated from the cold water pool off the coast of South America. Furthermore, the western equatorial Pacific is much too cool. Most of this cooling occurs during the first few years of the integration (see Fig. 8a). There are probably several reasons why the CGCM is unable to simulate a reasonable cold tongue.

First, the AGCM simulates trade winds too weak when forced by climatological SSTs. This results in a weak zonal SST gradient at the equator in the coupled simulation, which in turn reduces the strength of the trades. Therefore, due to the positive feedback between ocean and atmosphere, the annual mean wind stress (Fig. 1b) in the coupled simulation is even less than the stress simulated by the AGCM in the uncoupled control integration with prescribed climatological SST.

The second reason arises from the low resolution of the atmosphere model, because of which the Andes are not well resolved. This leads to persistent westerlies over the very eastern equatorial Pacific (Fig. 1b), which in turn leads to the very warm surface waters off the South American coast (Fig. 1a). Such behavior is also found in other coupled models, as described by Neelin et al. (1992).

Another reason for the weakness of the equatorial cold tongue might be related to the well-known inability of present state of the art AGCMs to simulate the lowlevel clouds over the southeastern Pacific, which leads

a)

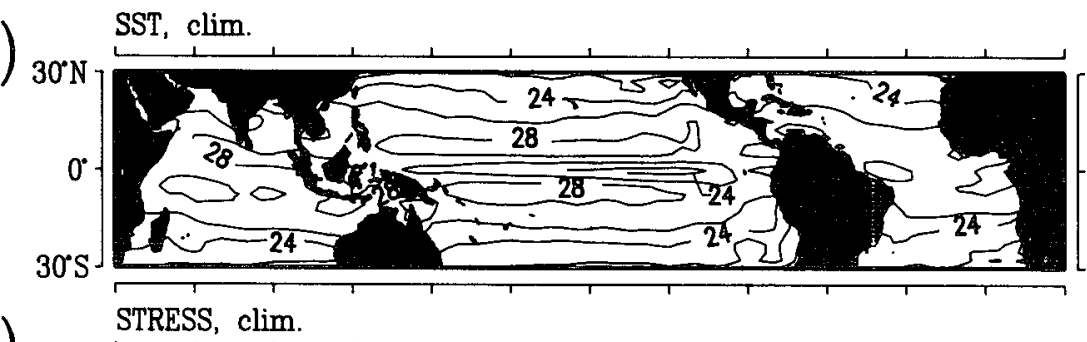

b)

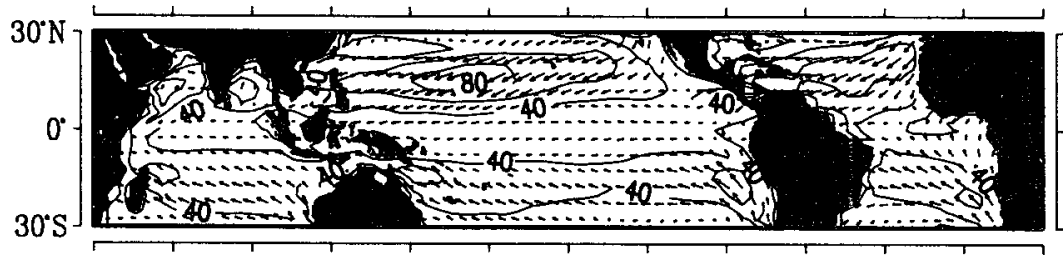

c)

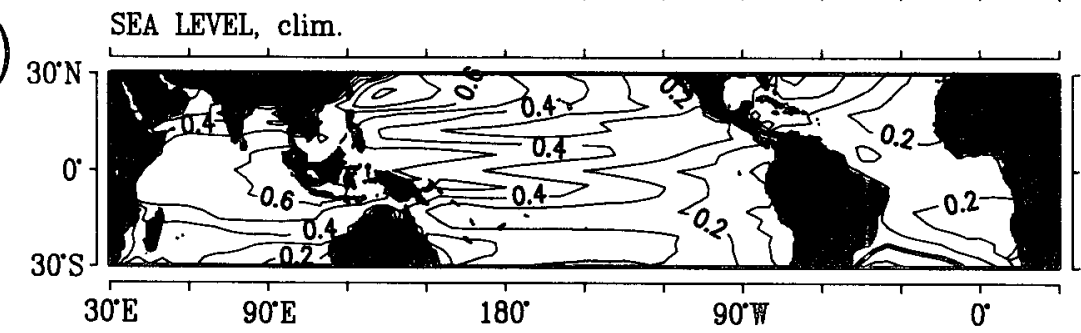

FIG. 1. Annual mean fields of the following quantities: (a) SST ( ${ }^{\circ} \mathrm{C}$ ),

(b) surface wind stress $(\mathrm{mPa})$, (c) sea level $(\mathrm{m})$. 
to an excess of incoming solar radiation and consequently to large errors in the net surface heat flux. This probably counteracts the coastal upwelling off the coast of South America due to increased local heating near the ocean's surface. On the other hand, the coastal upwelling might be too weak anyhow due to the coarse zonal resolution in the oceanic GCM.

The pattern of mean sea level (Fig. 1c) is simulated with more success than that of SST, showing an almost constant zonal gradient across the equatorial Pacific. Since sea level is a measure of heat content, this is consistent with a zonally asymmetric equatorial heat content. However, the sea level gradient across the equator is too weak compared to Levitus climatology. Like the SST, the annual mean heat flux (Fig. 2a) is symmetric about the equator, showing a gain of heat by the ocean in the equatorial region and a heat loss in the subtropics. The simulated annual mean precipitation over the tropical Pacific (Fig. 2b) is closely related to the SST (Fig. 1a) and is therefore also too zonal, with one band of heavy rain on either side of the equator. In the very eastern equatorial Pacific the CGCM simulates an isolated region of extremely strong rainfall. This feature can be attributed to the very warm SST simulated in this region (Fig. 1a).

In Figs. 3 and 4, the vertical structure of different oceanic quantities is presented. The structure of the temperature in the vertical plane parallel to the equator (Fig. 3a) shows the characteristic upward tilting of the isotherms in the eastern Pacific. This is consistent with a zonal pressure gradient in the upper ocean. The pressure gradient drives an undercurrent that also tilts upward to the east (Fig. 3b). However, because of the

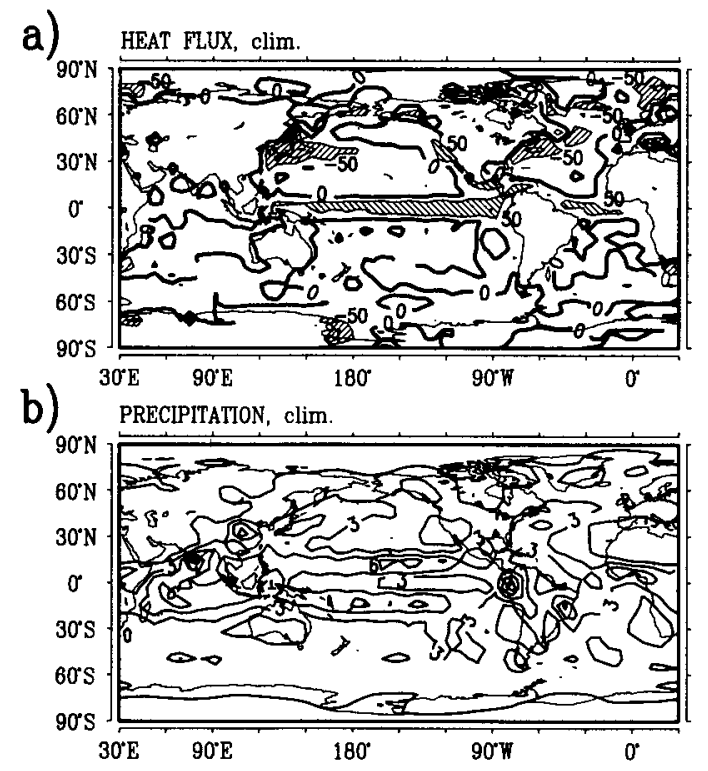

FIG. 2. Annual mean fields of (a) surface heat flux $\left(\mathrm{W} \mathrm{m}^{-2}\right)$, (b) precipitation $\left(\mathrm{mm} \mathrm{day}^{-1}\right)$.
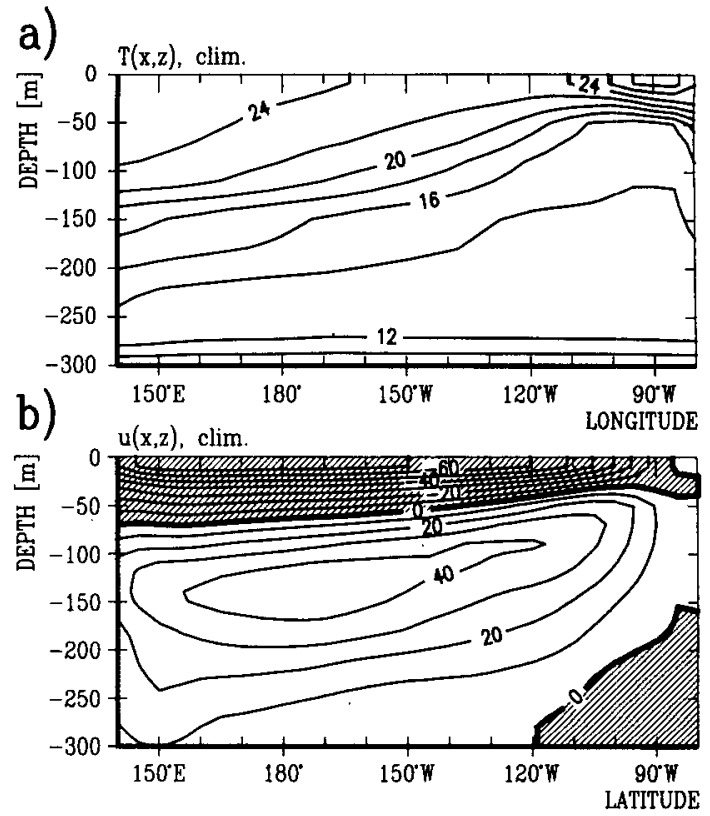

Fig. 3. Annual mean fields of (a) temperature $\left({ }^{\circ} \mathrm{C}\right)$ and (b) zonal currents $\left(\mathrm{cm} \mathrm{s}^{-1}\right)$ in a longitude-depth section at the equator.

weak winds and the resulting weak pressure gradient, the strength of the undercurrent is only about 50 $\mathrm{cm} \mathrm{s}^{-1}$. This is approximately half of the observed strength, which is on the order of $100 \mathrm{~cm} \mathrm{~s}^{-1}$.

The temperature structure in a meridional section near $150^{\circ} \mathrm{W}$ (Fig. 4a) shows north-south asymmetry with the isotherms tilting up to the north. Near the equator isotherms tilt upward above and downward below the core of the equatorial undercurrent (Fig. 4b) in response to the current shear, according to the thermal wind relation. The meridional circulation near the equator shows the classical picture of Ekman divergence near the surface and geostrophic inflow below the Ekman layer (Fig. 4c). Typical vertical velocities are of the order of $1 \mathrm{~m} \mathrm{day}^{-1}$ (Fig. $4 \mathrm{~d}$ ).

\section{b. Annual cycle}

The CGCM simulates an annual cycle that involves strong trades in northern fall (Fig. 6b) and weak trades in northern spring (Fig. 6a) near the equator. These changes in the trades are accompanied by changes in SST (Fig. 5). The equatorial cold water tongue is well developed during September (Fig. 5b) and only weakly developed during March (Fig. 5a). A westward phase propagation of the annual cycle along the equator is simulated (Figs. 8a,b). This westward propagation results from air-sea interactions, as was inferred from a more detailed analysis of the first harmonics of SST and zonal wind (not shown). Consistent with a westward-propagating SST mode, changes in zonal wind stress lead those in SST slightly in time and are dis- 

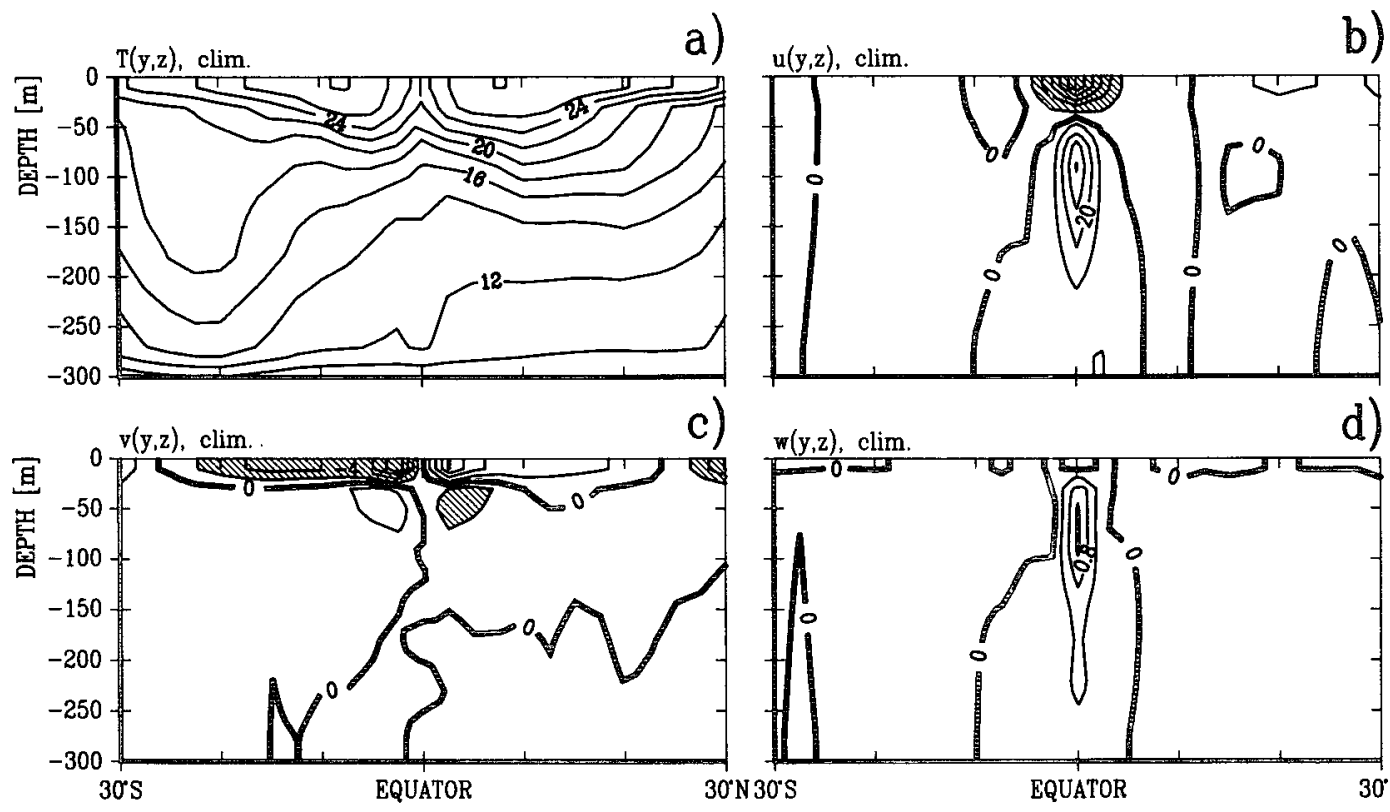

c)

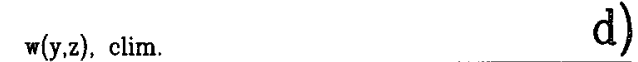

d)

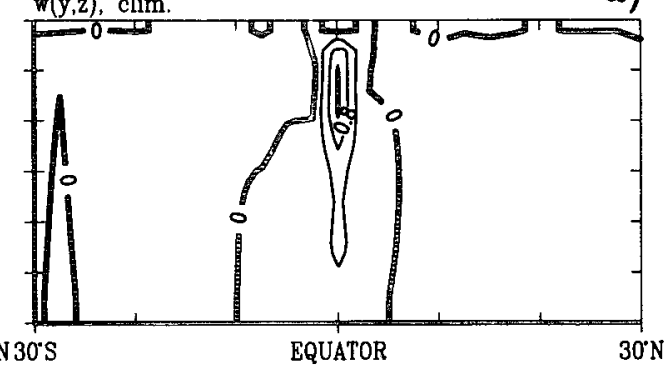

FIG. 4. Annual mean fields of (a) temperature $\left({ }^{\circ} \mathrm{C}\right)$, (b) zonal currents $\left(\mathrm{cm} \mathrm{s}^{-1}\right),(\mathrm{c})$ meridional currents $\left(\mathrm{cm} \mathrm{s}^{-1}\right)$, and $(\mathrm{d})$ vertical velocity $\left(\mathrm{m} \mathrm{day}^{-1}\right)$ in a meridional section in the central Pacific near $150^{\circ} \mathrm{W}$.

placed to the west of the SST signal. As described by Philander (1990), the observed annual cycle in the equatorial Pacific involves a similar coupled mode.

The evolution of SST outside the equatorial region is largely dominated by the movement of the sun and the incoming solar radiation. The summer hemisphere tends to warm up almost uniformly to a temperature of about $28^{\circ} \mathrm{C}$. This effect might be attributed to the applied Richardson number-dependent vertical mixing scheme in the ocean model, which due to the stabilization of the surface layers does not account for the downward transport of the heat during the summer months. In response to this unrealistic warming of the summer hemisphere, the simulated ITCZ moves between the hemispheres during the year (Fig. 7), whereas the observed ITCZ remains north of the equator throughout the year.

\section{The simulated ENSO}

As can be seen from Fig. 8, the CGCM simulates considerable interannual variability. This interannual variability is in many respects similar to the observed ENSO cycle. However, there are also a few important features that are not in accord with the observations. Among those, the most important deviation from the

a)

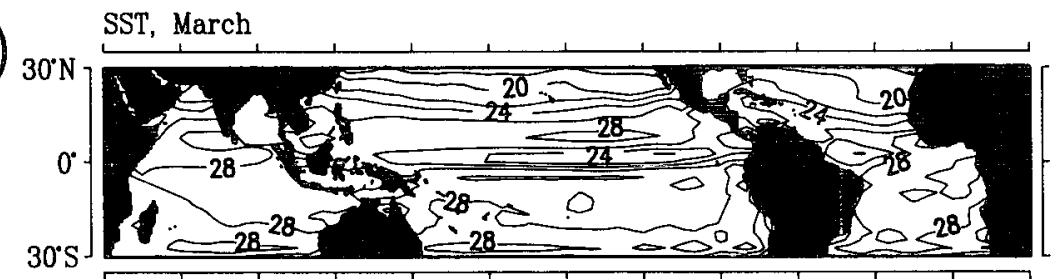

b)

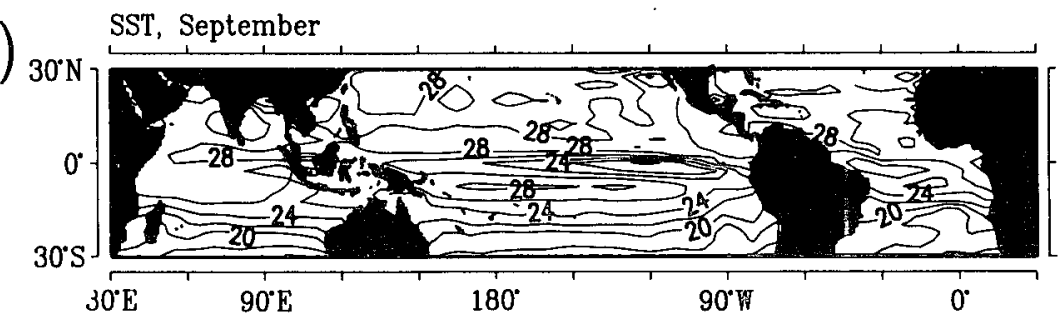

FIG. 5. Monthly mean SST $\left({ }^{\circ} \mathrm{C}\right)$ for (a) March and (b) September. 


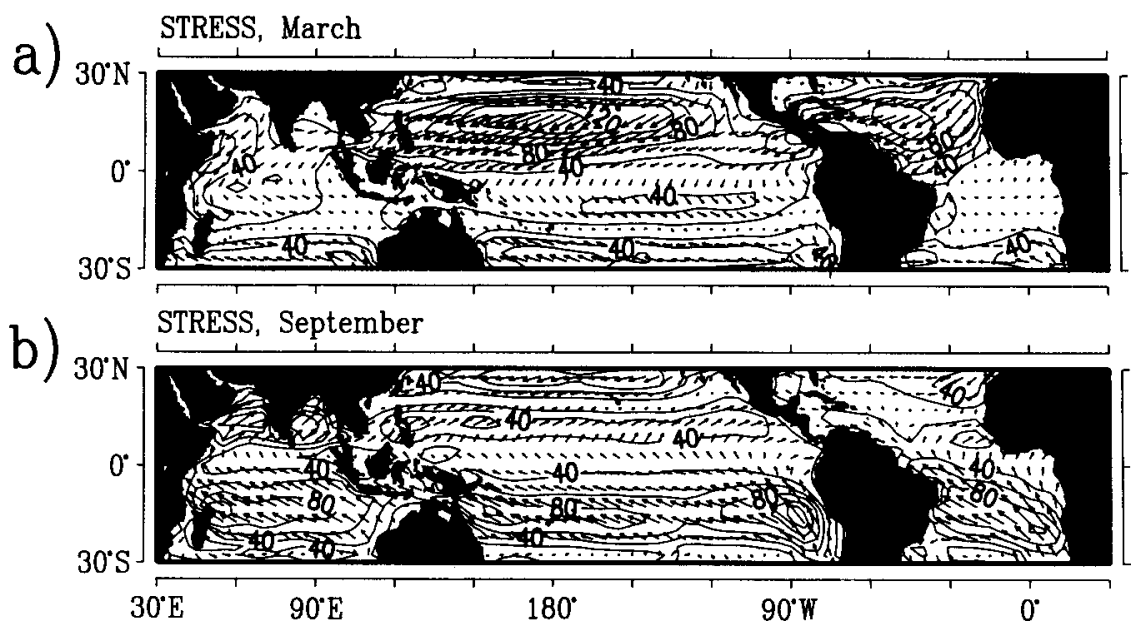

FIG. 6. Monthly mean surface wind stress $(\mathrm{mPa}$ ) for (a) March and (b) September.

observations is an underestimation of the meridional extent of the anomalies.

In Fig. 9, two indices of the simulated ENSO cycle are presented: the normalized Niño 3 SST anomalies and the anomalous pressure difference between the Indian Ocean and the eastern equatorial Pacific (SOI). Both indices show the most variability near periods of 3 years. Further, and consistent with observations, SST and SOI vary coherently out of phase; during periods of anomalously high SST, the pressure difference between the Indian Ocean and the Pacific attains a minimum resulting in weak trades, and vice versa.

a)

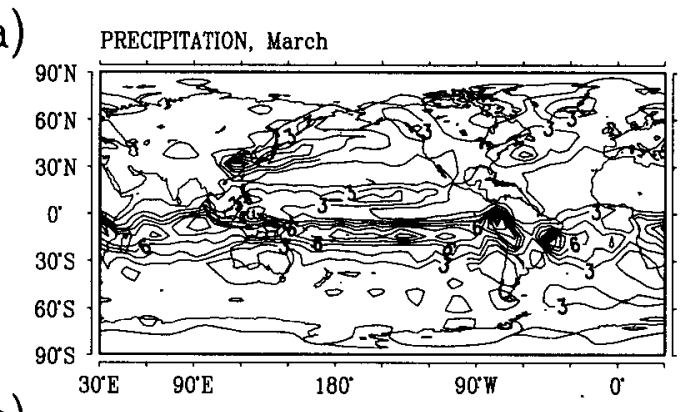

b)

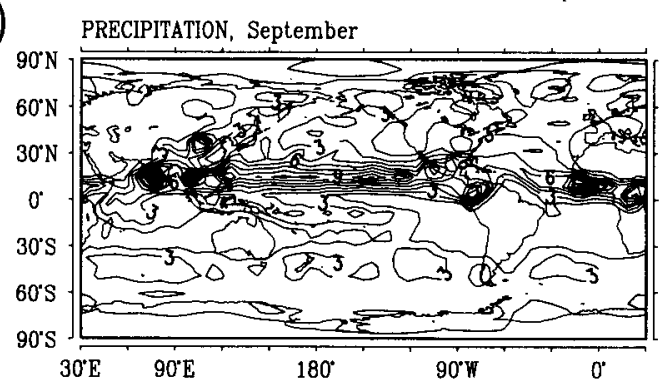

FIG. 7. Monthly mean precipitation $\left(\mathrm{mm} \mathrm{day}^{-1}\right)$ for (a) March and (b) September.

\section{a. Peak phase}

We first describe the spatial structure in different atmospheric and oceanic fields, when equatorial SST anomalies are fully developed, hereafter referred to as "peak phase." The leading empirical orthogonal function (EOF) of the low-pass filtered SST anomalies, which accounts for about $48 \%$ of the variance, is closely related to the simulated ENSO (Fig. 10). Its spatial a) SST [c]

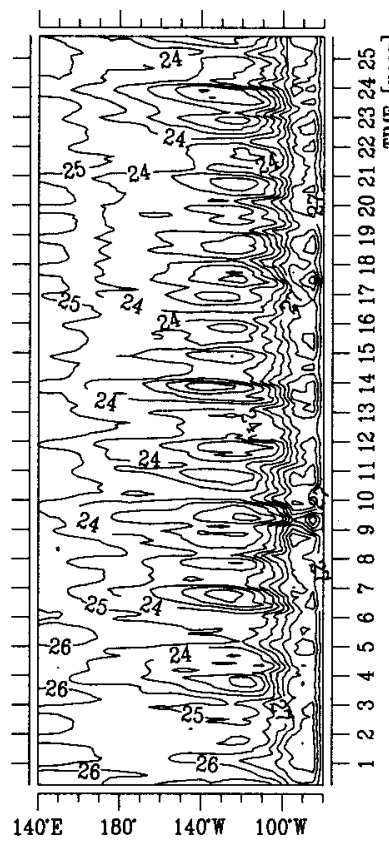

b) $T^{\mathbf{I}}[\mathrm{mPa}]$

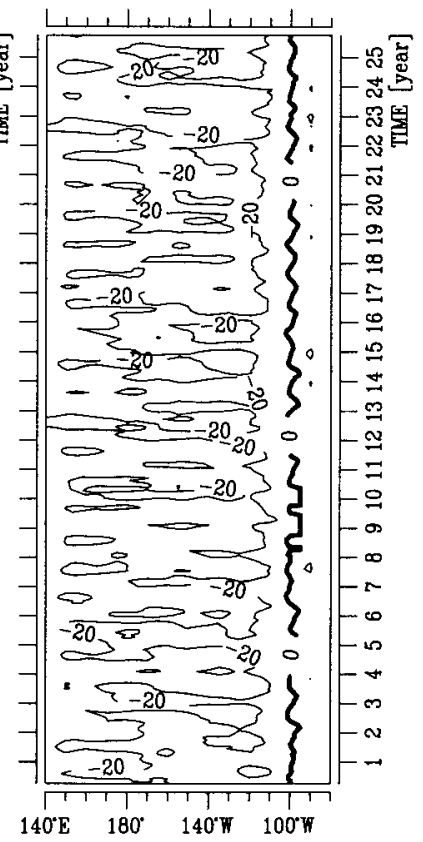

FIG. 8. Hovmoeller diagram of (a) SST $\left({ }^{\circ} \mathrm{C}\right)$ and (b) zonal wind stress $(\mathrm{mPa})$ along the equator. Smoothing by a 7 -month running mean has been applied. 


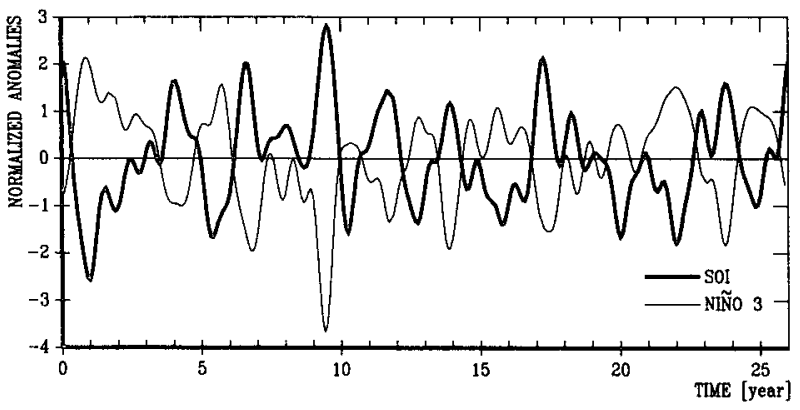

FIG. 9. By their standard deviations, normalized time series of the anomalous Niño- $3\left(5^{\circ} \mathrm{N}-5^{\circ} \mathrm{S}, 150^{\circ}-90^{\circ} \mathrm{W}\right) \mathrm{SST}$ and the anomalous pressure difference between the central Indian Ocean and the eastern equatorial Pacific Ocean (SOI).

pattern (Fig. 10a) shows maximum variability at the equator in the eastern Pacific near $120^{\circ} \mathrm{W}$. The corresponding EOF coefficient time series (Fig. 10b) is, as expected, very similar to the Niño 3 time series (Fig. 9 ). Interestingly, there is also simulated variability on longer time scales, as indicated by the slow modulation of the EOF coefficient time series.

In order to assess the variability patterns in other variables that go along with the SST variability, we computed their associated correlation patterns using the SST-EOF coefficient time series (Fig. 10b) as an index. That is, we simply regressed at each grid point the other quantities to the EOF time series. Since the EOF pattern is positive, the derived patterns correspond to El Niño (warm) conditions. La Niña (cold) conditions are given within this linear analysis simply by the mirror images of the derived patterns. We first describe

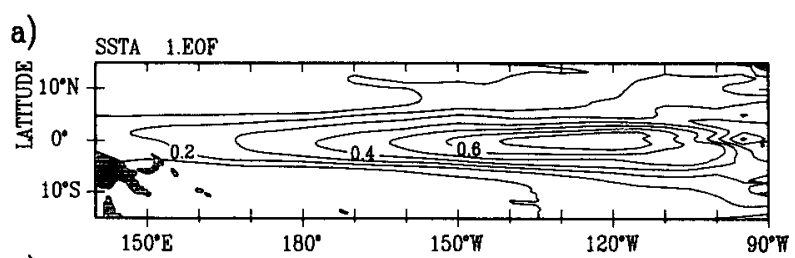

b)

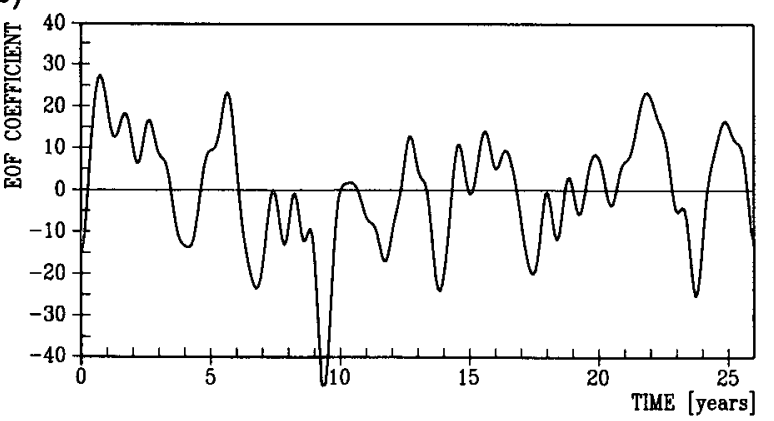

FIG. 10. First EOF of low-pass filtered SST anomalies (retaining periods longer than 12 months) for years 1 to 26: (a) EOF pattern (multiplied by 10); (b) EOF coefficient time series. the associated correlation patterns for certain atmospheric quantities (Figs. 11 and 12). The explained variances of these patterns with respect to the low-pass filtered monthly data amount to typically $30 \%$ in the centers of action (not shown). As implied by the time series of the SOI (Fig. 9), the associated correlation pattern of the sea level pressure anomalies (Fig. 11a) shows during the peak phase the well-known dipole with opposite changes in the western and eastern hemispheres; there is anomalous high pressure over Asia and anomalous low pressure over the eastern equatorial Pacific. Typical pressure differences are of the order of a few hectopascals.

Consistent with the analysis of the sea level pressure anomalies, the associated correlation pattern of the zonal wind stress anomalies shows westerly anomalies across the equatorial Pacific (Fig. 11b). Although the occurrence of westerlies during El Niños is observed, their simulated strength is much too weak with typical values of about $10 \mathrm{mPa}$ ( see also Fig. 14). Further, the anomalies are located too far to the east. In the observations the zonal wind stress anomalies are typically centered near the date line, whereas in our coupled simulation the anomalies occur in the region 170$130^{\circ} \mathrm{W}$. A similar failure can be seen in the coupled models of Zebiak and Cane (1987) and Philander et al. (1992). The strongest meridional shear occurs near $7^{\circ} \mathrm{N}$ and $7^{\circ} \mathrm{S}$, which favors the generation of heat content anomalies at these latitudes. The correlation pattern for the meridional wind stress component (Fig. 11c) shows anomalous convergence near the equator across the entire Pacific basin. This anomalous convergence is accompanied by rainfall anomalies (Fig.

a)

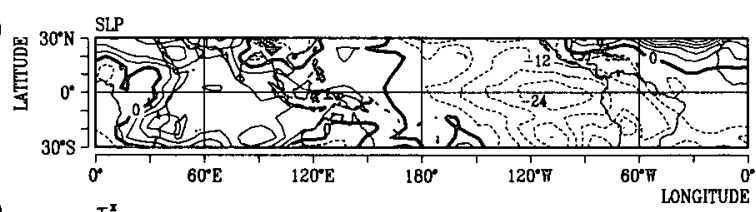

b)

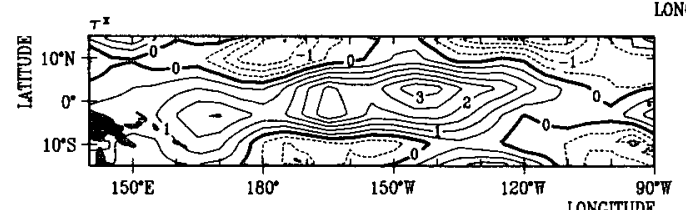

c)

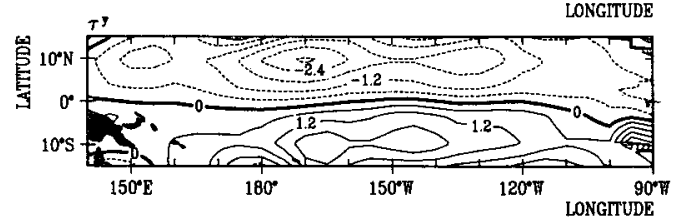

FIG. 11. Associated correlation patterns to the coefficient time series of the leading EOF of low-pass filtered SST anomalies (Fig. 10) for the following quantities: (a) sea level pressure (contour interval $6 \mathrm{~Pa}$ ), (b) zonal wind stress (contour interval $1 \mathrm{~m} \mathrm{~Pa}$ ), (c) meridional wind stress (contour interval $0.6 \mathrm{~m} \mathrm{~Pa}$ ). The patterns show the anomalies corresponding to a one standard deviation change in the EOF coefficient time series. 
a)

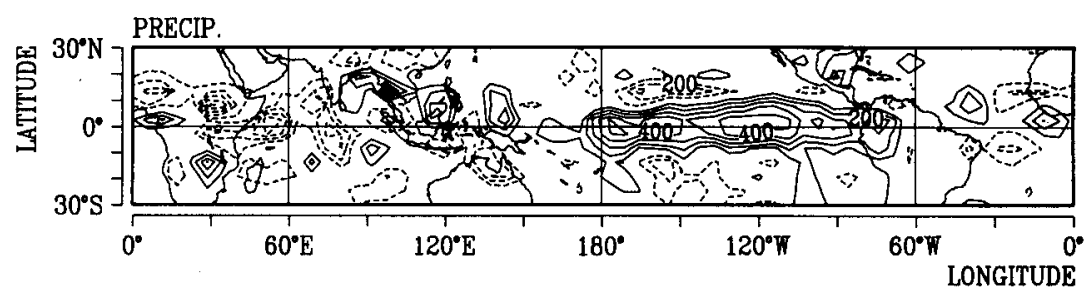

b)

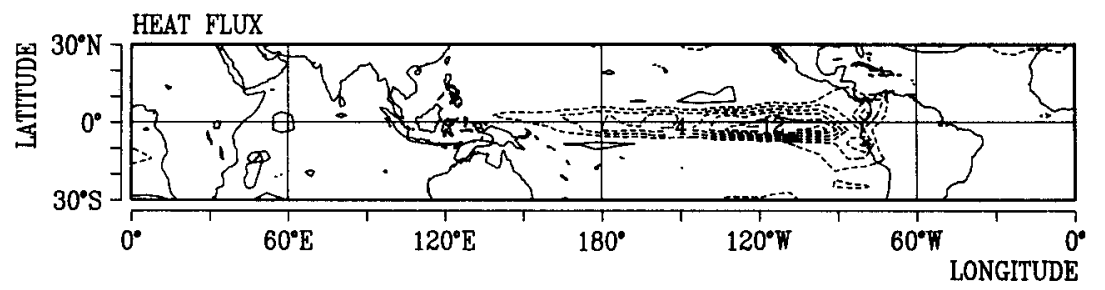

FIG. 12. As in Fig. 11 but for (a) precipitation (contour interval $10^{-11} \mathrm{~m} \mathrm{~s}^{-1}$ ) and (b) surface heat flux (contour interval $1 \mathrm{~W} \mathrm{~m}^{-2}$ ).

12a), which are also centered at the equator. Maximum rainfall anomalies are simulated between $180^{\circ}$ and $110^{\circ} \mathrm{W}$, attaining values of a few millimeters per day during strong events. Less rainfall is simulated over parts of eastern Asia and northern Australia, which is in accord with observational studies (e.g., Ropelewski and Halpert 1989). The net surface heat flux during the peak phase (Fig. 12b) is uniformly negative across the equatorial Pacific. This indicates that the heat flux acts as a negative feedback on the SST anomalies. This result is in accord with observational studies (e.g., Ramage et al. 1980) and with the analysis of Barnett et al. (1991), who investigated the surface heat flux simulated by our atmospheric GCM when driven with observed SSTs.

The associated correlation patterns in some oceanic variables were then analyzed (Fig. 13). Typical variances explained by the patterns are of the order of $50 \%$ in the centers of action, with respect to the filtered monthly data (not shown). The variability pattern in sea level (Fig. 13a) is reminiscent of Rossby and Kelvin wave structure. The anomalies in the east have a Gaussian shape with maxima at the equator and along the eastern boundary. Sea level anomalies in the western Pacific are strongest off the equator near $7^{\circ} \mathrm{N}$ and $7^{\circ} \mathrm{S}$ and are consistent with the spatial structure of the zonal wind stress anomalies (Fig. 11b), which show the strongest shear at these latitudes.

The vertical structures of temperature and zonal current anomalies along the equator (Figs. 13b,c) show considerable variability at subsurface levels. Most of these changes are associated with a reduction in the zonal pressure gradient in response to the above-described relaxation of the trade winds. Negative temperature anomalies are found in the western equatorial Pacific well below the surface (Fig. 13b), associated with a rise of the thermocline in this region. In contrast, the thermocline drops in the east, resulting in a warm- ing at the surface and at subsurface levels. The reduction of the east-west pressure gradient causes a deceleration of the equatorial undercurrent (Fig. 13c). At the surface, eastward current anomalies are generated by the westerly wind stress anomalies.

\section{b. ENSO mechanism}

Next, we address the question of the mechanism responsible for the simulated ENSO cycle. In Figs. 14
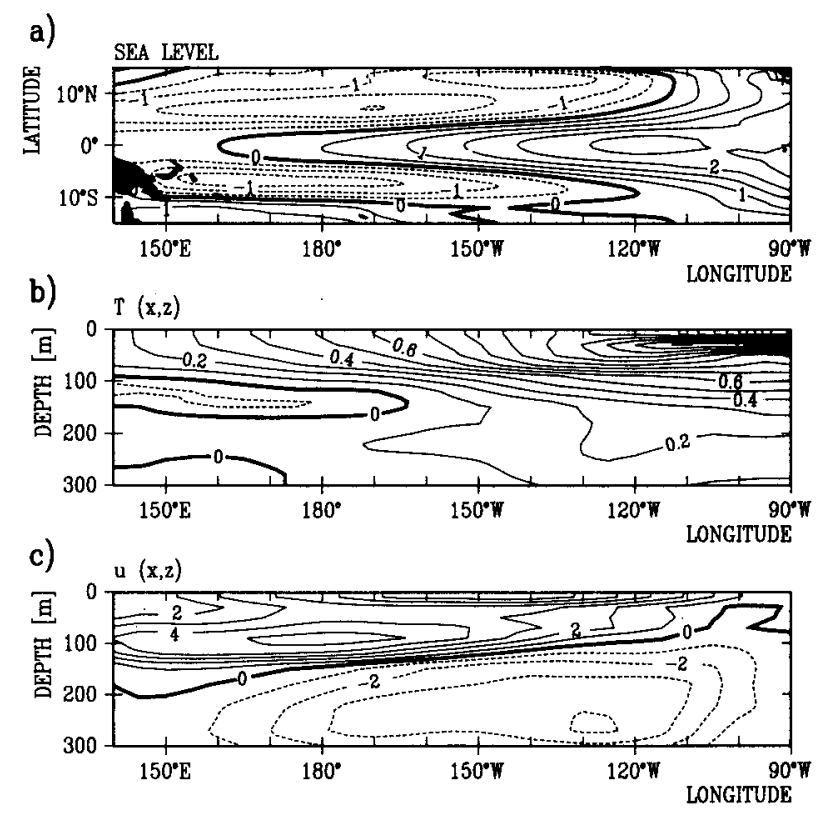

FIG. 13. Associated correlation patterns to the coefficient time series of the leading EOF of low-pass filtered SST anomalies (Fig. 10 ) for the following quantities: (a) sea level (contour interval 0.5 $\mathrm{cm})$, (b) $T(x, z)$ along the equator (contour interval $0.1^{\circ} \mathrm{C}$ ), (c) $u(x, z)$ along the equator (contour interval $1 \mathrm{~cm} \mathrm{~s}^{-1}$ ). 
and 15 , the time evolution of SST and zonal wind stress anomalies along the equator is presented, as well as sea level anomalies along the equator and $7^{\circ} \mathrm{N}$ during years 3-12 of the coupled integration. The propagation characteristics of the different quantities appear to be rather complicated. Both SST and zonal wind stress anomalies (Fig. 14) vary in phase and are largely dominated by a standing component in the western half of the Pacific. In the eastern Pacific, however, SST and zonal wind anomalies occasionally show westward propagation along the equator. In contrast, sea level anomalies at the equator (Fig. 15a) show slow eastward phase propagation in the western Pacific and have a strong standing component in the central and eastern Pacific. Sea level anomalies at $7^{\circ} \mathrm{N}$ (Fig. 15b) show westward propagation during most of the time. These propagation characteristics are partly consistent with both paradigms, most frequently offered to explain interannual variability in the tropical Pacific: Propagating sea level anomalies in association with standing SST and zonal wind stress anomalies are indicators of the delayed action oscillator, whereas the slow westward propagation of SST and zonal wind stress anomalies along the equator in the eastern equatorial Pacific might reflect the existence of a SST mode.

In the following, the evolution of anomalous conditions during one particular time period is briefly described, namely the evolution of the warm episode of

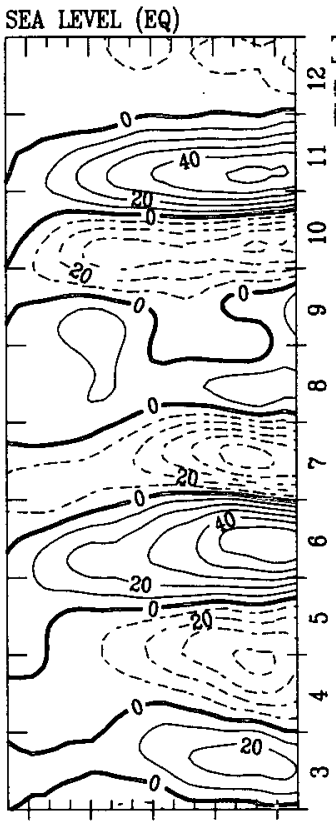

$150^{\circ} \mathrm{E} 180^{\circ} 150^{\circ} \mathrm{W} 120^{\circ} \mathrm{W} 90^{\circ} \mathrm{W}$

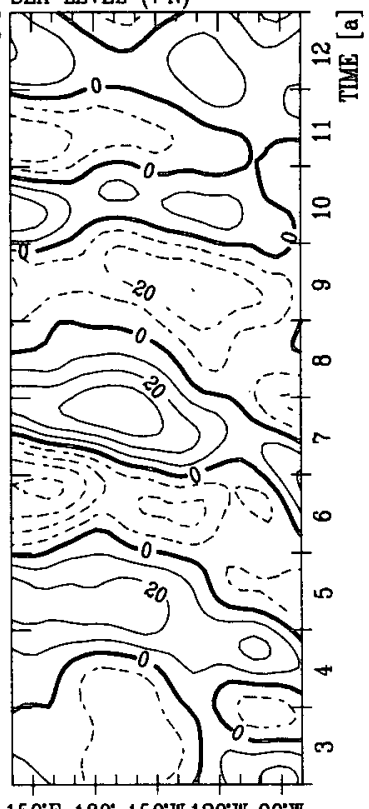

$150^{\circ} \mathrm{E} 180^{\circ} 150^{\circ} \mathrm{W} 120^{\circ} \mathrm{H} 90^{\circ} \mathrm{W}$
FIG. 15. Hovmoeller diagram of low-pass filtered sea level anomalies (contour interval $10 \mathrm{~mm}$ ) along the equator (left) and of lowpass filtered sea level anomalies (contour interval $10 \mathrm{~mm}$ ) at $7^{\circ} \mathrm{N}$ (right). Filtering retains variations with periods longer than 12 months.

year 6 and the subsequent cold episode of year 7, when the delayed action oscillator mode and the SST mode seem to coexist. Positive sea level anomalies occur prior to the warm event of year 6 at the western boundary as early as at the end of year 4 . At this time cold conditions still prevail at the surface (Fig. 14). The positive sea level anomalies in the western Pacific propagate slowly eastward along the equator (Fig. 15a) with a speed about one order of magnitude less than the speed of the gravest Kelvin wave mode. By the middle of year 5 the positive sea level anomalies have propagated across the Pacific and SST anomalies become positive all along the equator. So far, the evolution of anomalous conditions follows closely the delayed action oscillator.

The SST anomalies now start to propagate westward in the east, and they grow further due to the positive feedback between ocean and atmosphere. The positive SST anomalies force westerly wind stress anomalies that further strengthen the SST anomalies. During the height of the warm event, say during summer of year 6 , the westerly wind stress anomalies force off-equatorial sea level anomalies of opposite sign to those in the eastern equatorial Pacific. These negative anomalies propagate westward (Fig. 15b) and "reflect" at the western boundary into the equatorial wave guide. The anomalies then propagate slowly eastward along the

equator. At the same time negative SST and zonal wind
FIG. 14. Hovmoeller diagram of low-pass filtered SST anomalies (contour interval $0.5^{\circ} \mathrm{C}$ ) along the equator (left) and of low-pass filtered zonal surface wind stress anomalies (contour interval $5 \times 10^{-3}$ $\mathrm{Pa}$ ) along the equator (right). Filtering retains variations with periods longer than 12 months. 
stress anomalies develop in the east and propagate westward. The phase reversal in SST is completed in the very eastern part of the basin shortly after the offequatorial heat content anomalies have been generated. This suggests that conditions in the east are now dominated by the slow SST mode. The evolution of anomalies during the following year 7 appears to be influenced by both the delayed action oscillator and the slow SST mode.

A period when the slow SST mode seems to dominate the evolution of anomalous conditions is the warm phase of year 3. As theoretically expected, during this particular event zonal wind and SST anomalies exhibit a considerable spatial phase shift, with the maximum winds being located about $40^{\circ}$ to the west of the maximum SST anomalies (Fig. 14). Also, as expected from theoretical considerations, the anomalies in zonal wind stress lead those in SST shortly in time. Furthermore, there are no positive sea level anomalies emanating from the western boundary (Fig. 15a), which could explain the positive SST anomalies in the beginning of year 3. In contrast, the cold event of year 10 and the following warm event seem to be primarily related to the delayed action oscillator. The strong cold event of year 10 was, in addition, favored by the occurrence of a strong persistent easterly wind anomaly at the equator east of the date line, which forced an upwelling Kelvin wave pulse. No obvious propagation of either the SST or the zonal wind stress anomalies is found (Fig. 14), whereas heat content anomalies, as expressed by the sea level anomalies (Fig. 15a), clearly propagate in from the western boundary.

\section{c. POP-analysis}

In order to get more insight into the nature of the interannual variability, we performed in addition a statistical analysis based on the POP-technique (Hasselmann 1988; von Storch et al. 1988; $\mathrm{Xu}$ and von Storch 1990). The POP-technique is designed to extract the dominant modes of variability from a multidimensional dataset. The POPs are the eigenvectors of the system matrix obtained by fitting the data to a multivariate first-order Markov process. In general, POPs are complex, with real and imaginary parts $p_{1}$ and $p_{2}$. The associated complex eigenvalues provide information about a characteristic rotation period and a decay time. Because the POP amplitudes satisfy the standard damped harmonic oscillator equation, the evolution of the system in the two-dimensional POP space can be understood as a cyclic sequence of the patterns $p_{1}$ and $p_{2}$ :

$$
\cdots p_{1} \rightarrow-p_{2} \rightarrow-p_{1} \rightarrow p_{2} \rightarrow p_{1} \cdots \text {. }
$$

In our analysis, zonal wind stress, SST, and sea level anomalies are used simultaneously so that the POPs may be identified with the normal modes of our coupled model. Prior to the POP-analysis, the data were low-pass filtered, retaining periods longer than 12 months, and each of the three quantities was normalized with its mean field standard deviation. Our main focus is to investigate whether the POP analysis finds two coupled modes, which could be identified with the delayed action oscillator and the westward-propagating SST mode, or one mixed mode.

The POP-analysis revealed two dominant complex POPs accounting for about $28 \%$ and $16 \%$ of the variance, respectively. The two modes are statistically orthogonal. Both modes show aspects of delayed action oscillation and the slow SST mode. This is consistent with recent theoretical considerations by Neelin and Jin (1993), who show that delayed action oscillation and the slow SST mode are extremes of one mixed SST/subsurface dynamics mode. However, the most energetic POP mode seems to be dominated by delayed action oscillation, while the next energetic mode does show stronger evidence of the slow SST mode. The most energetic mode (Fig. 16) has a rotation period of 32 months and a decay time of 27 months. As pointed out by Xu and von Storch (1990), a better estimate of the rotation period can be obtained by a cross-spectral analysis of the corresponding POP coefficient time series (not shown), and this revealed a characteristic period of about 4 years. However, in any case, an estimate of characteristic time scales might suffer from the relatively short record length. The next most energetic POP mode is associated with a considerably shorter rotation period of 22 months and a decay time of 19 months. Cross-spectral analysis of the corresponding POP coefficient time series (not shown) revealed a slightly longer rotation period of about 2 years. Such a quasi-biennial mode is also found in observations (e.g., Barnett 1990; Rasmusson et al. 1990). Moreover, Münnich et al. (1991) argue that the observed ENSO period of about 4 years arises from period doubling of the biennial basic period. All other POPs either have time scales not relevant to ENSO or are statistically insignificant.

The real part $p_{1}$ of the dominant POP is clearly associated with the peak phase of the simulated ENSO. This can be inferred by comparing the three patterns (Figs. 16b,d,f) with the corresponding patterns derived from the EOF-analysis (Figs. 10a, 11b, 13a). SST anomalies in the eastern equatorial Pacific (Fig. 16d) are accompanied by wind stress anomalies of the same sign (Fig. 16b) and by the characteristic asymmetric sea level pattern (Fig. 16f). The imaginary part $p_{2}$ of the POP (Figs. 16a,c,e) describes the situation during the transition phase a quarter of the rotation period prior to the peak phase, that is, about 1 year earlier. Consistent with the delayed action oscillator, positive anomalies in equatorial heat content in the western equatorial Pacific (Fig. 16e) are found that were excited during the cold phase. (The cold phase is given by the patterns of the real part shown in Figs. 16b,d, $f$ but with reversed signs.) In the eastern equatorial Pacific, 
Transition phase, $P_{2}$ b) TAUX

Extreme phase, $P_{1}$
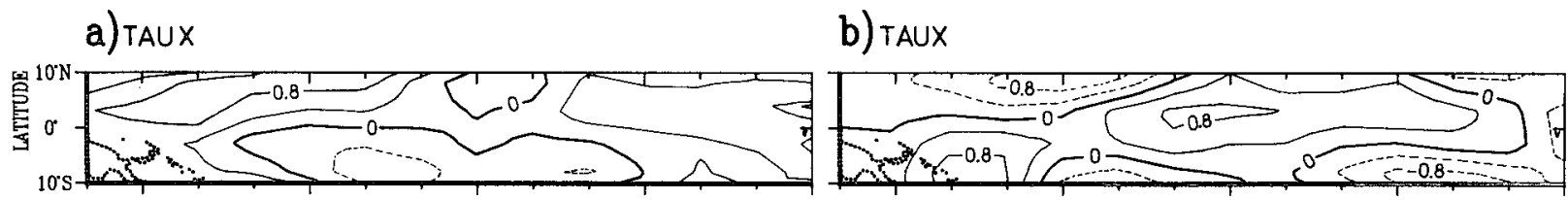

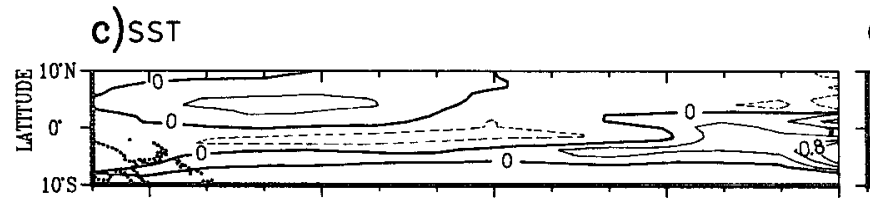

d) SST

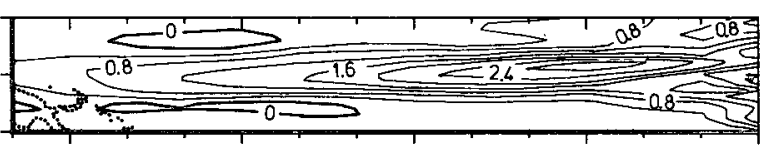

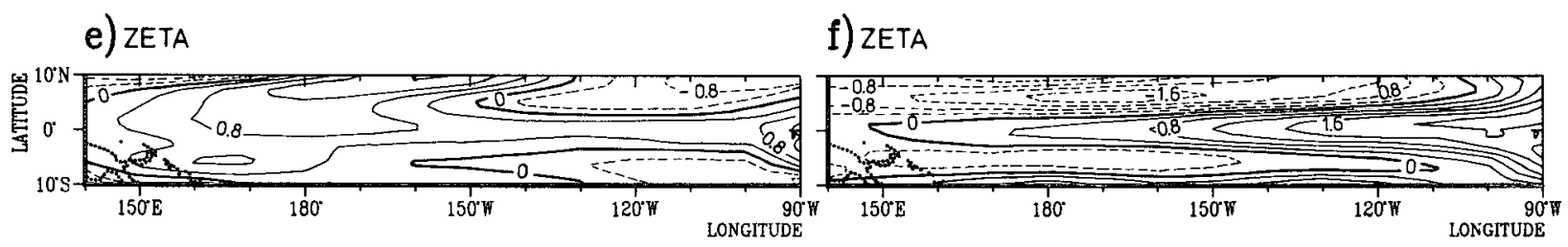

FIG. 16. Dominant POP mode of a combined POP analysis of anomalies in zonal wind (a, b), SST (c, d), and sea level (e, f) for years 3 to 26 of the CGCM run. The POP has a rotation time of 32 months and a damping time of 27 months. The explained variance amounts to $22.4 \%$. Prior to the analysis, the data have been subjected to low-pass filtering, retaining variations with periods longer than 12 months. The panels on the left show the anomalies during the transition phase about 8 months before the extreme phase, which is shown in the panels on the right.

however, positive anomalies in all three quantities are found prior to the peak phase. This suggests that anomalies propagate westward in this region. Further, the zonal wind anomalies are displaced to the west of the SST anomalies. This is in accord with the SST mode hypothesis. However, we hypothesize that for this POP mode, the delayed action oscillation part dominates the SST mode component. There are three reasons for this hypothesis. First, there is a strong heat content signal propagating into the equatorial wave guide during the transition phase (Fig. 16e). Second, the SST anomaly in the eastern Pacific is relatively weak during the transition phase (Fig. 16c) so that the SST variability can be described to first order as a standing oscillation. Finally, the response of the atmosphere to this weak SST anomaly in the eastern Pacific might be unrealistically high (Fig. 16a), because of the very warm surface waters simulated at the equator near the eastern boundary (Figs. 1a, 8a).

Interestingly, the POP mode also shows evidence of the occurrence of a westerly wind patch over the western Pacific centered north of the equator (Fig. 16a). This feature has been recognized for a long time and is described in several observational studies (e.g., Barnett 1983; von Storch et al. 1990; Latif et al. 1990). The occurrence of the westerly wind patch possibly results from an interaction of the Pacific trade wind field with the Asian monsoon, as described by Barnett (1983) and Barnett et al. (1991). This might indicate that ENSO is not a purely Pacific phenomenon. Such interactions, together with the variability in the Indian Ocean and in the Atlantic, will be investigated in a forthcoming paper.

In contrast to the first POP mode, the second POP mode (Fig. 17) exhibits a much weaker delayed response (Figs. 17e,f). On the other hand, the SST anomalies associated with this POP mode (Figs. 17c,d) show a distinct westward propagation in the eastern Pacific, which is consistent with a westward-propagating SST mode. Further, zonal wind stress anomalies at the equator (Figs. 17a,b) are displaced to the west of the SST anomalies. In the western Pacific anomalies near the equator in all three quantities are, in general, weak. We conclude that the second POP mode may be regarded as a westward-propagating SST mode. The existence of a delayed response does not contradict this 


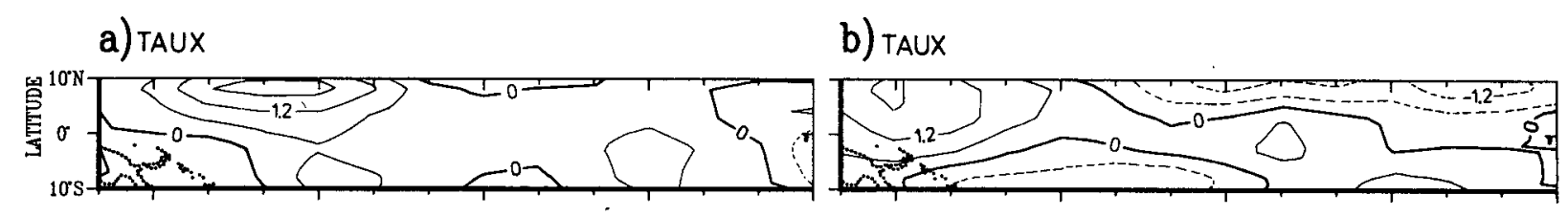

b) TAUX

c) SST

d) SST
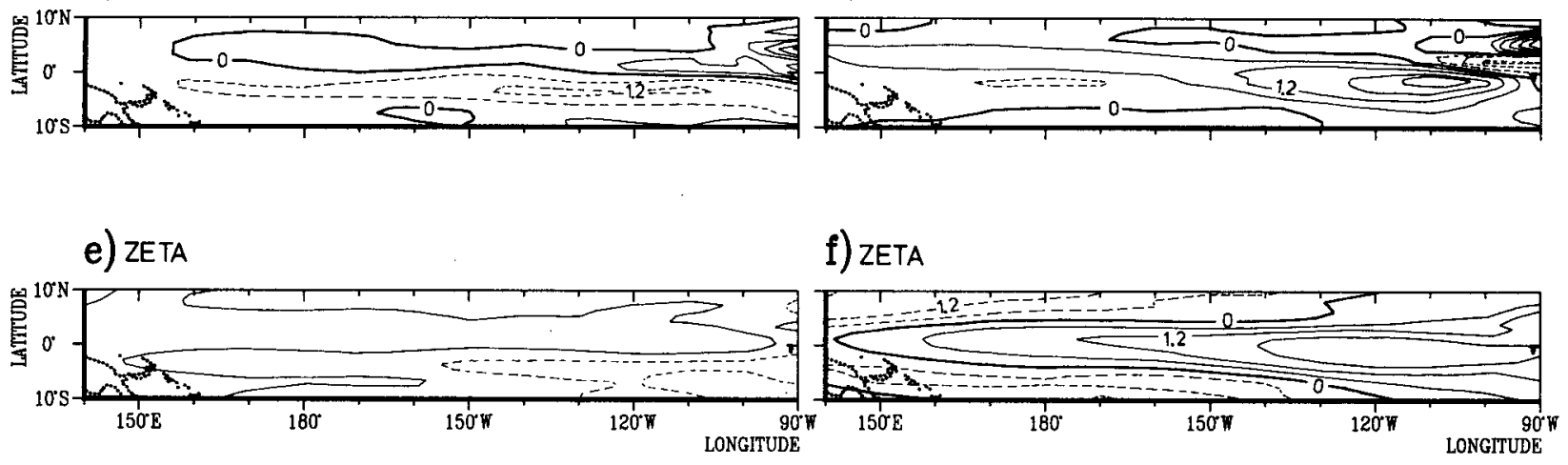

FIG. 17. Second POP mode of a combined POP analysis of anomalies in zonal wind (a, b), SST (c, d), and sea level (e,f) for years 3 to 26 of the CGCM run. The shown POP has a rotation time of 22 months and a damping time of 19 months. The explained variance amounts to $15.9 \%$. Prior to the analysis, the data have been subjected to low-pass filtering, retaining variations with periods longer than 12 months. The panels on the left show the anomalies during the transition phase about 6 months before the extreme phase, which is shown in the panels on the right.

interpretation because waves are expected to be excited by the wind anomalies that prevail during periods of well-developed SST anomalies (Fig. 17d). The second POP mode also shows some distinct north-south asymmetries in SST and zonal wind. Together with the quasi-biennial rotation period of this POP mode, this might indicate an interaction with the annual cycle.

\section{Sensitivity runs}

Additional uncoupled and coupled model runs were performed to investigate the ENSO mechanism further. The additional coupled integrations were carried out with simplified coupled ocean-atmosphere models, in which our atmospheric GCM was replaced by two linear feedback models and the ocean model by a Pacific version with slightly coarser vertical and horizontal resolution.

\section{a. Ocean response to periodic forcing}

First, we forced our ocean model in an uncoupled 10 -year run by periodic anomalous wind stress forcing.
By doing so, we can estimate to what degree the ocean is in equilibrium with the wind stress and if there is a delayed ocean response, as described by Philander (1990). In an earlier study, Cane and Sarachik (1981) derived analytical results for the response of a linear inviscid shallow water ocean to periodic forcing. The experiment was performed in such a way that over the tropical Pacific we added a purely zonal anomaly to the climatological wind stress derived from the 26-year run with the CGCM. Its spatial pattern (Fig. 18b) is given by the associated correlation pattern of the zonal wind stress anomalies derived from the coupled run (Fig. $11 \mathrm{~b}$ ). Its time evolution is sinusoidal with a period of 30 months, approximately the period of the dominant POP mode described above. In Fig. 18, the dominant POP mode derived from a simultaneous analysis of zonal wind, SST, and sea level anomalies is presented. This POP mode explains $70 \%$ of the total variance and has an oscillation period of 30 months and a decay time of 149 months. As in Figs. 16 and 17, the panels on the left show the conditions during the transition phase, when there is no wind anomaly (Fig. 18a), about 8 months before the peak phase. 
Transition phase, $P_{2} \quad$ Extreme phase, $P_{1}$
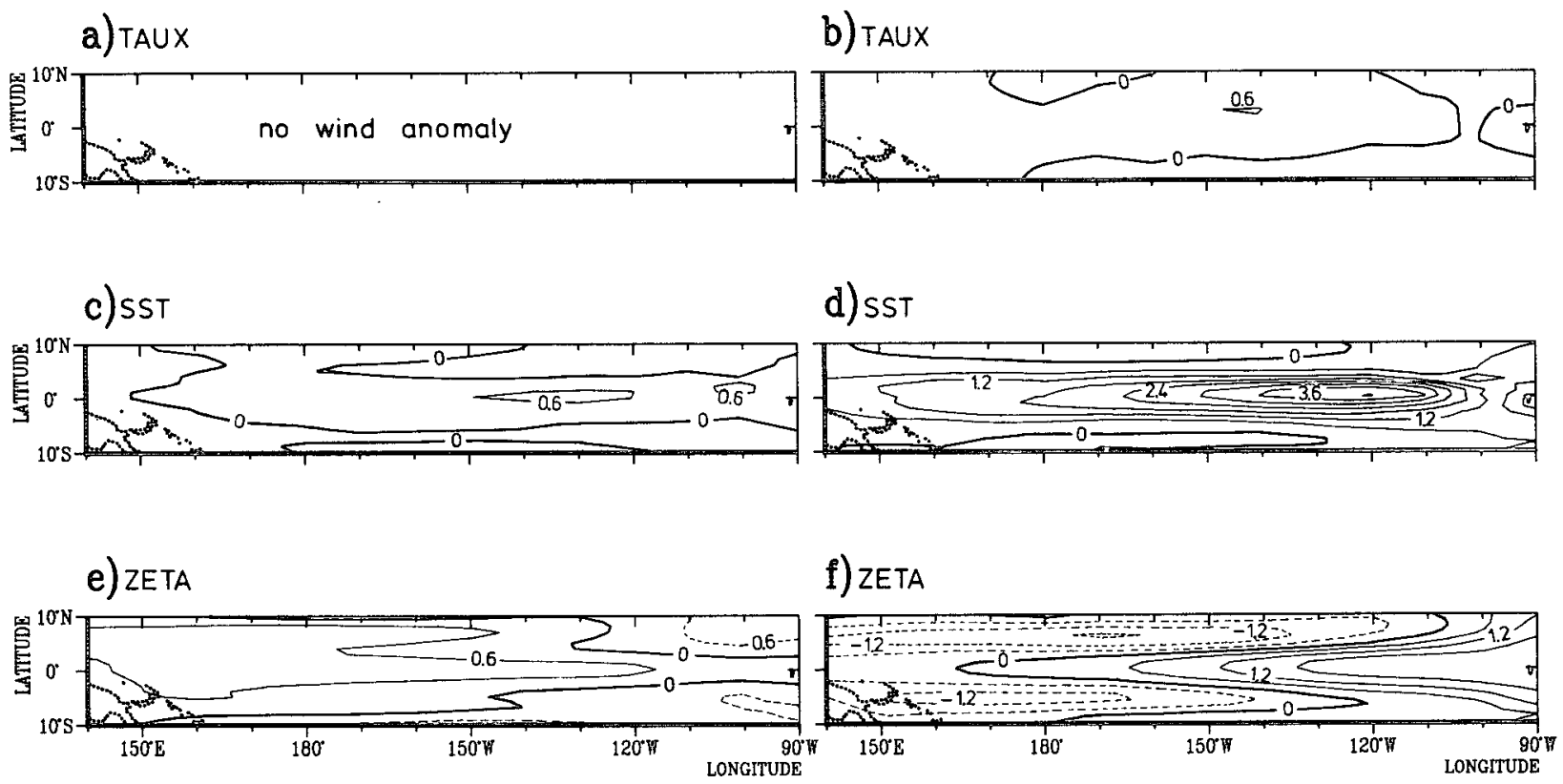

FIG. 18. Ocean response to peridiodic forcing. Combined POP analysis of anomalies in zonal wind (a, b), SST (c, d), and sea level (e, f) for the 10-year integration with the OGCM forced by periodic winds. The POP shown has a rotation time of 30 months and a damping time of 117 months. The explained variance amounts to $70.4 \%$. The panels on the left show the anomalies during the transition phase about 8 months before the extreme phase, which is shown in the panels on the right.

By definition, there is no wind anomaly during the transition phase (Fig. 18a). At this time, however, the ocean is still adjusting to the winds that prevailed during the preceding cold phase, which is given by the patterns presented in Figs. 18b,d, f, but with reversed sign. Positive heat content anomalies generated in the western Pacific off the equator during the preceding cold phase have now propagated into the equatorial wave guide (Fig. 18e) and are accompanied by eastward current anomalies (not shown). The evolution of equatorial heat content as expressed by the sea level anomalies is similar to the evolution of the dominant POP mode derived from the CGCM run (Figs. 16e, f). SST anomalies (Fig. 18c) have switched sign and are now positive in the central and eastern Pacific. Typical SST anomalies are of the order of a few tenths of a degree. This experiment shows clearly that the oceanic GCM is not in equilibrium with the wind field at this frequency. This result is consistent with the study of Cane and Sarachik (1981) and demonstrates that delayed action oscillation is possible in coupled experiments. Further, the similarities of the POP patterns with those of the dominant POP mode of the coupled run support the assumption that the dominant coupled
POP mode can be identified with the delayed action oscillator.

\section{b. Runs with simplified coupled models}

In order to explore the conditions under which variability associated with delayed action oscillation or the slow SST mode can occur, coupled integrations with hybrid GCMs were also performed in which our AGCM was replaced by simpler linear atmosphere models. In these runs, delayed action oscillation occurred when the wind response to SST anomalies was highly asymmetric. We first coupled a linear steadystate atmosphere model (Opsteegh and Van den Dool 1980; Opsteegh and Mureau 1984) to the ocean model. This atmosphere model shows, for the parameters chosen, an almost symmetric wind response when driven with observed SST anomalies (Latif and Villwock 1990). That is, the simulated wind anomalies are spatially in quadrature to the SST anomalies, and the easterly and westerly branches have about the same strength. Such a coupled system favors the occurrence of the westward-propagating SST mode. Both SST and zonal wind show distinct westward propagation. The 
a) Model I

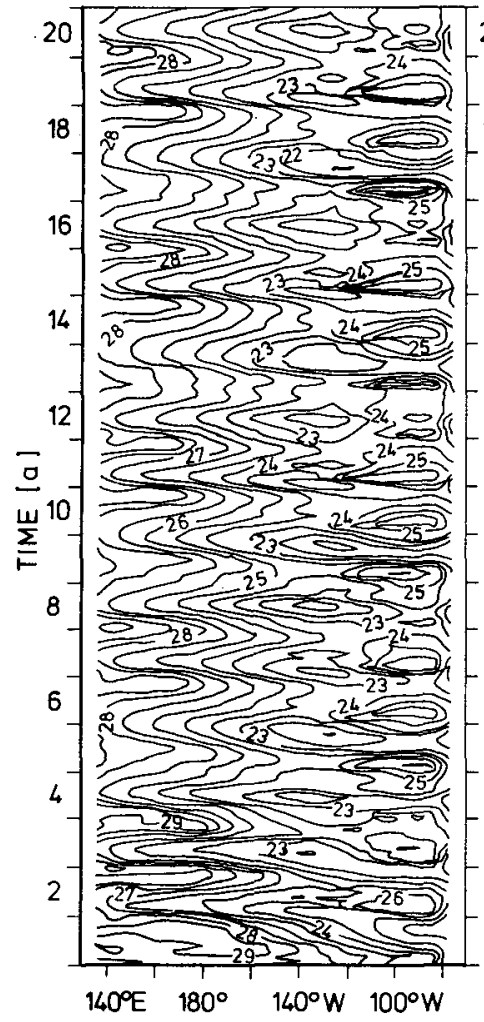

b) Model II. standard

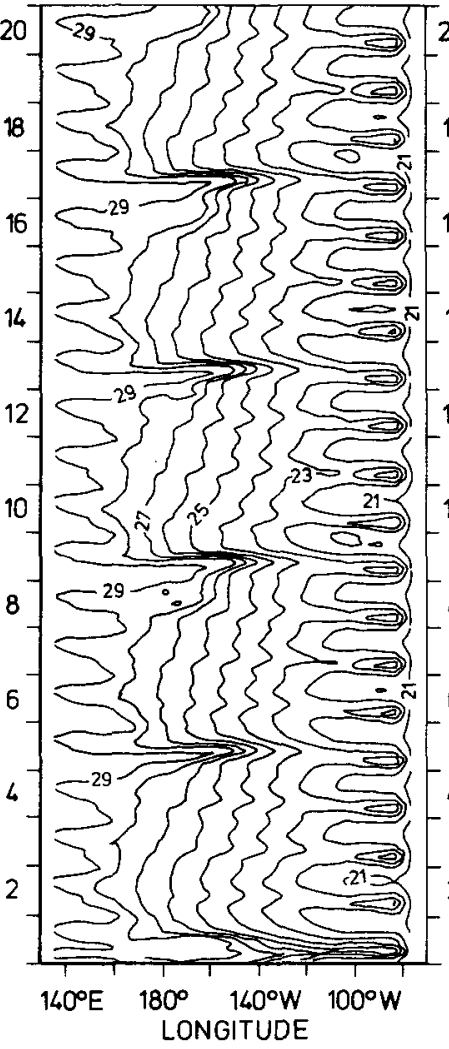

c) Model II. $1.1 * \bar{\tau}$

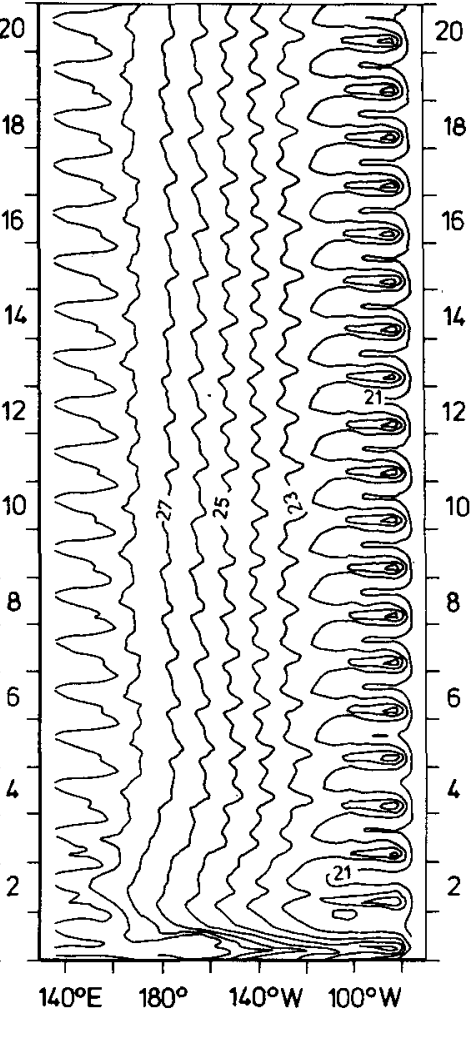

FIG. 19. Hovmoeller diagrams of SST $\left({ }^{\circ} \mathrm{C}\right)$ along the equator for three coupled runs with simplified coupled ocean atmosphere models. (a) Ocean model coupled to the atmosphere model described in Opsteegh and Van den Dool (1980) and Opsteegh and Mureau (1984), (b) ocean model coupled to the empirical feedback model (standard background wind stress), and (c) as in run (b) but with $10 \%$ stronger mean background wind stress.

typical oscillation period is about 16 months. Overall, the oscillation obtained, shown in Fig. 19a in terms of the full SST along the equator, is in many respects similar to that described by Neelin (1990).

In the second run, an empirical atmosphere model is coupled to the ocean. This atmosphere model is similar to the one described by Latif and Flügel (1991) and was obtained by a regression analysis using the observed SST and the local surface stress anomalies. [Latif and Flügel (1991), however, used in the regression the ocean model SST anomalies from a run with observed winds instead of the observed SST anomalies.] The wind response of the empirical atmosphere model when forced by observed SST anomalies is confined to the western and central Pacific. This strong asymmetry arises from the fact that there exists no systematic relationship between SST and surface wind stress anomalies in the eastern Pacific. The oscillation that occurred using the empirical atmosphere (Fig. 19b) is completely different from the previous one. An investigation of the heat content anomalies (not shown) clearly showed the propagation characteristics required for delayed action oscillation. Further, the SST and wind stress anomalies (not shown ), though not strictly exhibiting a standing oscillation, are at least dominated by a standing component. The characteristic period of the oscillation has changed to about 4 years. This difference in the characteristic oscillation periods obtained in the two coupled runs further support the hypothesis that the two dominant POPs derived from the CGCM run may be identified with the delayed action oscillator mode and with the slow SST mode.

The runs with the two simplified coupled models may be regarded as extreme cases because of the very different response characteristics of the two atmosphere models used. The two runs show, however, that both types of coupled modes, the delayed action oscillator and the SST mode, can occur using the same ocean model. Considering the wide variety of possible behaviors in atmospheric GCMs, it appears likely that in coupled general circulation experiments either the two modes can degenerate to one mode or can coexist as in the CGCM run under investigation.

\section{c. Sensitivity to mean upwelling}

Finally, we address the question of why the present version of the CGCM oscillates, whereas the previous 
version (Latif et al. 1988a) did not. Our hypothesis is that the previously applied flux correction technique (Sausen et al. 1988) used to couple the models in Latif et al. (1988a) was the main reason for the absence of interannual variability. In order to prove this hypothesis, one would have to rerun the present version of our CGCM with the flux correction. However, due to restrictions in the computer facilities, this is not feasible. We therefore used our simplified coupled model based on the empirical feedback to explore how the flux correction can affect the interannual variability. By using the flux correction, one adds constant offsets to the interactive quantities. The offsets, which are determined from uncoupled control runs, are basically given by the model errors. In the case of our AGCM, the offset in the zonal wind stress near the equator would consist of easterlies. As described in Latif et al. (1988a), the strength of these additional easterlies is about as strong as the model wind stress itself, resulting in a considerable strengthening of the equatorial upwelling. It is known from stability analysis that the mean upwelling acts as a negative feedback on the SST anomalies so that the strengthening of the upwelling might reduce the variability in a coupled integration. Since the stress anomalies simulated by our AGCM when forced by observed SSTs are also significantly weaker than observed, the ratio of mean to anomalous wind stress is changed by the application of the flux correction.

In order to explore the sensitivity of coupled systems to the strength of the equatorial upwelling, we varied the mean background wind stress in our sensitivity runs. This can easily be done, because the empirical feedback model computes only stress anomalies, which are added to the prescribed mean background wind stress to drive the ocean model in coupled runs. For consistency, prior to a coupled run, the ocean model was spun up with the background wind stress under investigation. The major result of these additional sensitivity runs is that even a modest increase in the background wind stress can entirely suppress interannual variability. If, for instance, the mean wind stress is increased by only $10 \%$ compared with that in the above described standard run (Fig. 19b), the coupled system is stable (Fig. 19c). This supports our hypothesis that the application of the flux correction inhibited oscillations in the coupled model of Latif et al. (1988a).

\section{Summary and discussion}

We have conducted an extended-range climate integration with a fully coupled ocean-atmosphere general circulation model (CGCM). The CGCM consists of a high-resolution, zonally global ocean model and a low-order spectral atmosphere model. The model was forced by seasonally varying insolation. We have investigated the climatology and interannual variability simulated in the tropical Pacific only. Overall, the CGCM simulates reasonably well the time-averaged mean state, as well as the variability on seasonal and interannual time scales. In particular, the CGCM simulates ENSO-type interannual variability with a preferred time scale of about 3 years.

Coupled GCM integrations are useful in studying the nature of coupled feedbacks and in verifying the coupled feedbacks proposed by more simple models. We have shown that coupled feedbacks play a crucial role on a wide variety of time scales in our simulation. The climate drift, the annual cycle, and the interannual variability involve such coupled feedbacks. Although we found these coupled feedbacks in some respects consistent with those suggested by conceptual or simplified coupled models, the variability in our CGCM simulation appears to be much more complex.

In addition, coupled GCM integrations represent much more stringent tests for the individual model components than uncoupled integrations in which conditions are in general constrained by the use of observed boundary conditions. One example is the interaction of the vertical mixing in the ocean with the incoming solar radiation. Due to the stabilization of the upper ocean by the incoming solar radiation, our Richardson number-dependent mixing scheme failed to transport the heat down into deeper ocean layers. As a consequence, the ocean surface in the summer hemisphere warmed up almost uniformly. Such an effect was not observed in the various uncoupled integrations that we performed with the ocean model. A similar experience is reported by the group at the University of California Los Angeles (Neelin et al. 1992). Since this coupled feedback is highly nonlinear, it has a serious influence only in integrations with seasonally varying insolation and not in annual mean integrations. Other problems in the individual model components, such as too weak trade winds, are also amplified by the coupling.

Nevertheless, despite the problems in simulating a realistic climatology, the CGCM realistically simulates the interannual variability in the tropical Pacific. As already discussed by Neelin et al. (1992), the presence or absence of interannual variability does not appear to depend on climate drift. The trades in our coupled integration, for instance, are much too weak so that equatorial upwelling is also weak. A similar model deficiency is reported from the coupled general circulation model of Philander et al. (1992). We have shown further that coupled systems are extremely sensitive to the strength of equatorial upwelling, which is also noted in many other studies (e.g., Neelin 1991; Wakata and Sarachik 1991). An increase of mean background wind stress by only $10 \%$ inhibited oscillations in one of our sensitivity experiments with a simplified coupled model. Further, coupled general circulation models that simulate a realistic climatology do not necessarily simulate interannual variability (Neelin et al. 1992). These results indicate that in some coupled models there exist a compensation of errors, leading to interannual variability. 
An important result from the current study is certainly that the interannual variability is related to two different coupled modes, which can occur individually or which might coexist. In past studies with coupled GCMs (Meehl 1990; Philander et al. 1992; Lau et al. 1992), the interannual variability was attributed to either the (generalized) delayed action oscillator hypothesis (Philander et al. 1992) or to the slow SST mode (Meehl 1990; Lau et al. 1992). As described above, interannual variability in our coupled GCM simulation shows evidence of both the delayed action oscillator and the slow SST mode. During most of the time, the two coupled modes seem to coexist with eastward propagation of heat content mainly in the western and westward propagation of SST and zonal wind anomalies in the eastern equatorial Pacific. However, the two coupled modes do not exist in their pure form. The delayed action oscillator mode also shows aspects of the slow SST mode, and vice versa. This behavior is in accord with theoretical considerations by Neelin and Jin (1993), who showed that in certain locations of the parameter space, the two modes can merge into one mode.

Our additional simulations with simplified coupled models showed that the spatial structure of the atmospheric feedback plays an important role in the nature of the oscillations found. The slow SST mode is favored when there is a considerable wind response over the eastern equatorial Pacific, therefore, advective processes in the mixed layer associated with Ekman dynamics dominated the processes associated with changes in subsurface temperatures. By using an atmospheric feedback model, whose response is mostly confined to the western Pacific, we were also able to obtain variability of the delayed action oscillator type. As proposed by Neelin and Jin (1993), this indicates that the relative contributions of advection within the mixed layer associated with Ekman dynamics and the effect of thermocline perturbations to the SST tendency are important quantities in determining the nature of interannual variability. However, as shown by our CGCM run, such parameters are not necessarily constant during the course of the integration, resulting in a very complex structure of interannual variability.

In Part II of this paper, we shall investigate the performance of the CGCM over the Indian and Atlantic oceans. In particular, we are interested in the interaction between the Asian monsoon and ENSO. Work is also under way to estimate the skill of our CGCM in ENSO prediction studies. For this purpose, a large ensemble of predictions will be carried out in order to estimate reliable scores.

Acknowledgments. We would like to thank Profs. Klaus Hasselmann and Mark Cane for carefully reading an earlier version of the manuscript and for their valuable suggestions. We thank Profs. David Neelin, George Philander, and Ed Sarachik for many fruitful discussions. Special thanks to Mr. Andreas Villwock and Mr. Moritz Flügel for programming assistance. We thank Ms. Marion Grunert and Mr. N. Noreiks for preparing the diagrams. This work was partly financed by the European Community Climate Program under Grant EV4C-0035-D(B) and by the 'Körber Projekt.' The calculations have been carried out at the Deutsches Klimarechenzentrum (DKRZ).

\section{REFERENCES}

Barnett, T. P., 1983: Interaction of the monsoon and the Pacific trade wind system at interannual time scales. Part $I$ : The equatorial zone. Mon. Wea. Rev., 111, 756-773.

- 1990: The interaction of multiple time scales in the tropical climate system. J. Climate, 3, 269-285.

- M. Latif, E. Kirk, and E. Roeckner, 1991: On ENSO physics. J. Climate, 4, 487-515.

Biercamp, J., and H. von Storch, 1987: Exchange of energy and momentum at the ocean's surface. Climate simulations with the ECMWF T21 model in Hamburg. Large Scale Atmospheric Modelling Rep. No. 1, G. Fischer, Ed., 83-94. [Available from Meteorologisches Institut der Universität Hamburg, Bundesstraße 55, D-2000 Hamburg 13, Germany.]

Busalacchi, A. J., K. Takeuchi, and J. J. O'Brien, 1983: Interannual variability of the equatorial Pacific. Hydrodynamics of the Equatorial Ocean, J. C. J. Nihoul, Ed., Elsevier Oceanogr. Ser., Vol. 36.

Cane, M. A., and E. S. Sarachik, 1981: The response of a linear baroclinic equatorial ocean to period forcing. J. Mar. Res., 39, 651-693.

Fischer, G., 1987: Climate simulations with the ECMWF T21 model in Hamburg. Large Scale Atmospheric Modelling Rep. No. 1, G. Fischer, Ed., 94 pp. [Available from Meteorologisches Institut der Universität Hamburg, Bundesstraße 55, D-2000 Hamburg 13, Germany.]

Gill, A. E., 1982: Atmosphere-Ocean Dynamics. Academic Press.

Gordon, C., 1989: Tropical ocean-atmosphere interactions in a coupled model. Phil. Trans. Roy. Soc. London, A329, 207-223.

Hasselmann, K., 1988: PIPs and POPs: The reduction of complex dynamical systems using principal interaction and oscillation patterns. J. Geophys. Res., 93(D9), 11 015-11021.

Latif, M., 1987: Tropical ocean circulation experiments. J. Phys. Oceanogr., 17, 246-263.

- and A. Villwock, 1990: Interannual variability in the tropical Pacific as simulated by coupled ocean-atmosphere models. $J$. Mar. Sys., 1, 51-60.

, and M. Flügel, 1991: An investigation of short range climate predictability in the tropical Pacific. J. Geophys. Res., 96(C2), 2661-2673.

- J. Biercamp, H. von Storch, and F. W. Zwiers, 1988a: A ten year climate simulation with a coupled ocean-atmosphere general circulation model. Max-Planck-Institut für Meteorologie, Rep. No. 21. [Available from Max-Planck-Institut für Meteorologie, Bundesstraße 55, D-2000 Hamburg 13, Germany.]

,-- , and $-1988 \mathrm{~b}$ : The response of a coupled oceanatmosphere general circulation model to wind bursts. J. Atmos. Sci., 45, 964-979.

$\longrightarrow,-\longrightarrow$, and M. J. McPhaden, 1990: Simulation of ENSO related surface wind anomalies with an atmospheric GCM forced by observed SST. J. Climate, 3, 509-521.

Lau, N.-C., 1985: Modeling the seasonal dependence of the atmospheric response to observed El Niños in 1962-76. Mon. Wea. Rev., 113, 1970-1996.

, S. G. H. Philander, and M. J. Nath, 1992: Simulation of ENSOlike phenomena with a low-resolution coupled GCM of the global ocean and atmosphere. J. Climate, 5, 284-307.

Levitus, S., 1982: Climatological atlas of the world ocean. NOAA Prof. Paper No. 13, U.S. Govt. Printing Office, Washington, D.C., 173 pp., 17 microfiche. 
Luksch, U., and H. von Storch, 1992: Modeling the low-frequency sea surface temperature variability in the North Pacific. J. Climate, 5, 893-906.

McCreary, J. P., 1983: A model of tropical ocean-atmosphere interaction. Mon. Wea. Rev., 111, 370-387.

Meehl, G. A., 1990: Seasonal cycle forcing of El Niño-Southern Oscillation in a global coupled ocean-atmosphere GCM. J. Climate, 3, 72-98.

Münnich, M., M. A. Cane, and S. E. Zebiak, 1991: A study of selfexcited oscillations of the tropical ocean-atmosphere system. Part II: Nonlinear cases. J. Atmos. Sci., 48, 1238-1248.

Neelin, J. D., 1990: A hybrid coupled model general circulation model for El Niño studies. J. Atmos. Sci., 47, 674-693.

- 1991: The slow sea surface temperature mode and the fastwave limit: Analytic theory for tropical interannual oscillations and experiments in a hybrid coupled model. J. Atmos. Sci., $584-606$.

- , and F. F. Jin, 1992: Modes of interannual tropical oceanatmosphere interactions-a unified view. Part II: Analytical results in the weak coupling limit. J. Atmos. Sci., submitted.

- M. Latif, M. A. F. Allaart, M. A. Cane, U. Cubasch, W. L. Gates, P. R. Gent, M. Ghil, C. Gordon, N. C. Lau, C. R. Mechoso, G. A. Meehl, J. M. Oberhuber, S. G. H. Philander, P. S Schopf, K. R. Sperber, A. Sterl, T. Tokioka, J. Tribbia, and S. E. Zebiak, 1992: Tropical air-sea interaction in general circulation models. Clim. Dyn., in press.

Opsteegh J. D., and H. M. van den Dool, 1980: Seasonal differences in the stationary response of a linearized primitive equation model: prospects for long-range forecasting? J. Atmos. Sci., 37, 2169-2185.

- , and R. Murau, 1984: Description of a 15 layer steady state atmospheric model. University of Maryland. Dept. of Meteorology, Report No. SR-84-19.

Pacanowski, R. C., and S. G. H. Philander, 1981: Parameterization of vertical mixing in numerical models of tropical oceans. $J$. Phys. Oceanogr., 11, 1443-1451.

Philander, S. G. H., 1990: A review of simulations of the Southern Oscillation. Proc. Int. TOGA Scientific Conf. Proc. Honolulu, World Climate Research Programme, WCRP-43, WMO/TDNo. 379.

- and A. D. Seigel, 1985: Simulation of El Niño of 1982-83. Coupled Ocean-Atmosphere Models, J. C. J. Nihoul, Ed., Elsevier, Oceanography Ser., No. 40.
-, R. C. Pacanowski, N. C. Lau, and M. J. Nath, 1992: A simulation of the Southern Oscillation with a global atmospheric GCM coupled to a high-resolution, tropical Pacific ocean GCM. J. Climate, 5, 308-329.

Ramage, C. S., C. W. Adams, A. M. Hori, B. J. Kilonski, and J. C. Sadler, 1980: Meteorological Atlas of the 1972 El Niño. $101 \mathrm{pp}$. [Available from Dept. of Meteorology, University of Hawaii, Honolulu.]

Rasmusson, E. M., X. Wang, and C. F. Ropelewski, 1990: The biennial component of ENSO variability. J. Mar. Sys., 1, 71-96.

Ropelewski, D. F., and M. S. Halpert, 1989: Precipitation patterns associated with the high index phase of the Southern Oscillation. J. Climate, 2, 268-284.

Sausen, R., K. Barthel, and K. Hasselmann, 1988: Coupled oceanatmosphere models with flux correction. Clim. Dyn., 145-163.

Schopf, P. S., and M. J. Suarez, 1988: Vacillations in a coupled oceanatmosphere model. J. Atmos. Sci., 45, 549-566.

Seager, R., 1989: Modeling tropical Pacific sea surface temperature 1970-87. J. Phys. Oceanogr., 19, 419-434.

Sterl, A., 1991: Manual for the primitive equation OGCM as used for ENSO studies and the interface to ECHAM. [ Available from Max-Planck-Institut für Meteorologie, Bundesstraße 55, D-2000 Hamburg 13, Germany.]

von Storch, H., 1988: Climate simulations with the ECMWF T21 model in Hamburg. Large Scale Atmospheric Modelling Rep. No. 4, H. von Storch, Ed. [Available from Meteorologisches Institut der Universität Hamburg, Bundesstraße 55, D-2000 Hamburg 13, Germany.]

$\longrightarrow$, T. Bruns, I. Fischer-Bruns, and K. Hasselmann, 1988: Principal oscillation analysis of the 30 to 60 day oscillation in a GCM. $J$. Geophys. Res., 93(D9), 11 022-11 036.

$\ldots$ - U. Weese, and J.-S. Xu, 1989: Simultaneous analysis of spacetime variability: Principal oscillation patterns and principal interaction patterns with application to the Southern Oscillation. Z. Meteor., 40, 99-103.

Wakata, Y., and E. S. Sarachik, 1991: Unstable coupled atmosphereocean modes in the presence of a spatially varying background state. J. Atmos. Sci., 48, 2060-2077.

Xu, J.-S., and H. von Storch, 1990: Principal oscillation patternsPrediction of the state of ENSO. J. Climate, 3, 1316-1329.

Zebiak, S. E., and M. A. Cane, 1987: A model El Niño-Southern Oscillation. Mon. Wea. Rev., 115, 2262-2278. 